\title{
Influences Motivating Smokers in a Radon-Affected Area to Quit Smoking
}

Christopher J Groves-Kirkby

Ph.D., School of Science and Technology, The University of Northampton, Avenue Campus,

St. Georges Avenue, Northampton, NN2 6JD, UK

Tel.: + 44 (0) 1604893837

Email:chris.groves-kirkby@northampton.ac.uk

Karen Timson

Pubic Health Department, Northamptonshire County Council, Guildhall Road, Northampton, NN1 1DN, UK

Tel.: +44 (0) 1604236086

Email: karen.timson@northants.nhs.uk

George Shield

Northamptonshire Healthcare NHS Foundation Trust, Bevan House, Kettering Parkway South, Venture Park, Kettering, Northants, NN15 6XR, UK

Tel.: +44 (0) 1536480340

Email: george.shield@nhfts.nhs.uk

Antony R Denman

Ph.D., School of Science and Technology, The University of Northampton, Avenue Campus,

St. Georges Avenue, Northampton, NN2 6JD, UK

Tel.: +44 (0) 1604893837

Email:tony.denman@northampton.ac.uk

Stephen Rogers

Public Health Department, NHS Northamptonshire, Francis Crick House, Moulton Park, Northampton, NN3 6BF, UK

Tel.: +44 (0) 1604651635

Email: stephen.rogers@northants.nhs.uk

Prof. Jackie Campbell

Ph.D., School of Health, The University of Northampton, Boughton Green Road, Northampton, NN2 7AL, UK

Tel.: +44 (0) 1604892010

Email: Jackie.campbell@northampton.ac.uk

Prof. Paul S Phillips

Ph.D., School of Science and Technology, The University of Northampton, Avenue Campus,

St. Georges Avenue, Northampton, NN2 6JD, UK

Tel.: +44 (0) 1604893366

Email:paul.phillips@northampton.ac.uk

Merryn Ekberg

Ph.D., School of Health, The University of Northampton, Boughton Green Road, Northampton, NN2 $7 A L, U K$

Tel.: +44 (0) 1604892523

Email:merryn.ekberg@northampton.ac.uk

Corresponding Author:

Christopher J Groves-Kirkby

as above 


\title{
Influences Motivating Smokers in a Radon-Affected Area to Quit Smoking
}

\begin{abstract}
Aims

Domestic radon gas concentrations in parts of the United Kingdom are sufficiently high to increase lung-cancer risk among residents, and recent studies have confirmed that the risk of smokers developing lung-cancer is significantly enhanced by the presence of radon. Despite campaigns encouraging residents of radon-affected areas to test and remediate their homes, public response to the risks posed by radon remains relatively modest, particularly among smokers and young families, limiting health benefits and cost-effectiveness achievable by remediation.
\end{abstract}

The observation that smokers, who are most at risk from radon, are not being targeted by current radon remediation campaigns, prompted assessment of the value of smoking-cessation initiatives in reducing radon-induced lung-cancers by reaching at-risk sub-groups of the population hitherto uninfluenced by radon awareness programmes. This study addresses the motivation of current quitters in a designated Radon-Affected Area, using a postal questionnaire sent around one year after the quit attempt.

\section{Methods}

Residents of the Northamptonshire radon-affected area who had joined the smoking-cessation programme between July and September 2006 and who remained tobacco-free at four weeks, were subsequently invited to participate in a questionnaire-based investigation into factors affecting their decision to cease smoking. From an initial population of 445 eligible individuals, 205 of those contacted by telephone after 12 months agreed to complete postal questionnaires, and unsolicited questionnaires were sent to a further 112 participants for whom telephone contact had proved impossible. 103 completed questionnaires were returned and analysed, principal tools being MannWhitney and Kruskal-Wallis tests. 


\section{Results}

Individuals decide to quit smoking from self-interest, principally on health grounds, and regard the effects their smoke on others, particularly children and unborn babies, as less significant. The risk of developing respiratory, coronary/cardiac or cancerous conditions provides greatest motivation to the decision to quit, with knowledge of radon amongst the lowest ranked influences.

\section{Conclusion}

This study confirms that quitters place risks to their personal health as the highest factors influencing their decision to quit, and health professionals should be aware of this when designing smoking-cessation initiatives. As radon risk is ranked very low by quitters, there would appear to be potential to raise radon awareness through smoking-cessation programmes, with the objective of increasing the uptake and success rate of such programmes and encouraging participation in radon remediation programmes.

\section{Keywords}

radon, carcinogen, environmental pollution, smoking-cessation, questionnaire-based study 


\section{Influences Motivating Smokers in a Radon-Affected Area to Quit Smoking}

\section{INTRODUCTION}

\section{Smoking-Cessation in the United Kingdom}

Smoking-related diseases, principally lung-cancer, chronic obstructive pulmonary disease, cardiovascular disease and other cancers, are estimated to cost the United Kingdom (UK) National Health Service (NHS) $£ 1.5$ bn per year ( $0.16 \%$ of gross domestic product), including $£ 127 \mathrm{~m}$ to treat lung-cancer alone. ${ }^{1}$ Since tobacco-smoking was identified as the most significant risk factor for lung-cancer, health education campaigns have targeted reduction of smoking prevalence. ${ }^{2}$ These, together with other tobacco control policies, have been largely successful; UK smoking prevalence fell from 45\% in 1974 to $28 \%$ (East Midlands, 27\%) in the late 1990s, to 22\% (East Midlands, $20 \%$ ) in 2006, and to $21 \%$ (East Midlands, 19\%) in 2009 (the latest year for which official figures are available). ${ }^{3}$

To support these efforts, the NHS offers smoking-cessation services, counselling and supporting smokers wanting to quit, ${ }^{4}$ users of these services being prescribed pharmacological aids to increase their chance of successfully quitting. In Northamptonshire (East Midlands), smoking-cessation services are offered through General Practitioners, Pharmacists and dedicated Stop Smoking programmes, (with a different, dedicated programme for pregnant who are pregnant), the Government target of 1000 smokers quitting per year being achieved. The criterion for quitting is self-reported abstinence that is biochemically verified by exhaled carbon monoxide (CO) monitoring ${ }^{5}$ at four weeks, with follow-up questionnaires at 26 and 52 weeks; these latter are less reliable, as the response rate is low and not $\mathrm{CO}$-validated.

Although smoking cessation programmes have been extensively developed in recent years, it is proving increasingly difficult to reduce smoking rates further, and it is currently felt that a heterogeneous portfolio of approaches is required to reach 'hard-to-engage' populations. ${ }^{6}$ With current evidence indicating the existence of 'difficult-to-reach' core populations of determined 
smokers, our recent studies indicate the possibility of extending awareness of full spectrum of lungcancer risk agents if potential quitters were provided with radon safety and remediation information during their interaction with smoking cessation programmes in radon Affected Areas.

These issues have been reviewed in our own work ${ }^{7,8}$ and that of others ${ }^{9}$

\section{Radon in the Domestic Environment}

Radon, a naturally-occurring radioactive gas with variable geographical occurrence, concentrates in the built environment, including within domestic properties, contributing around $50 \%$ to the average UK background radiation dose. ${ }^{10}$ At high concentrations in the Colorado uranium mines, radon was found to be associated with increased lung-cancer risk, and extrapolation from these studies indicated that residents of high-radon areas are similarly at risk. ${ }^{11}$ Apart from limited in vitro and animal experiments, the principal evidence for the combined effects of radon and cigarette smoke on lung-cancer incidence is the uranium miners' studies. ${ }^{11}$ Recent domestic studies confirm a multiplicative interaction, ${ }^{12}$ with smokers estimated to be at least 25 times more at risk of radoninduced lung-cancer than non-smokers. ${ }^{13}$

Responding to the health threat posed by domestic radon, the former UK National Radiological Protection Board (now part of the Health Protection Agency) established a residential Action Level of $200 \mathrm{~Bq} \cdot \mathrm{m}^{-3}$ and declared as Radon-Affected Areas geographical entities where $>1 \%$ of measurements in existing housing reported radon concentrations exceeding that level. ${ }^{14}$ Remediation is generally straightforward, usually involving the installation of an under-floor sump and associated extraction pump, although in certain situations, more extreme measures may be required. ${ }^{15}$

Northamptonshire, a rural county in the English East Midlands with $7.1 \%$ of homes tested exceeding the Action Level, ${ }^{16}$ was declared a Radon-Affected Area in $1992 .{ }^{17}$ Despite intensive campaigns, only $40 \%$ of Northamptonshire houses have been tested and only $10 \%$ of householders finding raised levels proceed to remediate their homes. ${ }^{18}$ Radon remediation studies in 
Northamptonshire, addressing NHS properties, ${ }^{19}$ schools,${ }^{20}$ workplaces, ${ }^{21}$ and private homes, ${ }^{22-28}$ demonstrate that remediation programmes offer cost-effective routes to environmental management. If completed, the Northamptonshire remediation programme would compare favourably with other health initiatives, e.g. mammography screening, ${ }^{23}$ with greater health benefit accruing for a smoker in a high-radon dwelling from quitting smoking than from remediating the house and continuing smoking. ${ }^{7}$

\section{Smoking in a High-Radon Environment}

The observation that smokers, who are most at risk from radon, are not being targeted by current radon remediation campaigns, ${ }^{29,30}$ prompted assessment of the value of smoking-cessation initiatives in reducing radon-induced lung-cancers by targeting at-risk population sub-groups hitherto uninfluenced by radon remediation programmes. A postal questionnaire administered to householders who had identified elevated radon levels, and who had consequently remediated their homes, showed $9 \%$ smoking incidence, compared with the UK national average of $28.8 \%{ }^{29}$ suggesting that current strategies to reduce domestic radon are not reaching those most at risk. To explore this apparent discrepancy further, the study reported here addresses the motivation of current quitters in a designated Radon-Affected Area, using a postal questionnaire administered one year after the commencement of the quit attempt.

\section{METHOD}

\section{Study Population}

The smoking-cessation data reported here formed part of a study of factors affecting the decision to stop smoking, given ethical approval by NHS Nottingham Research Ethics Committee in August 2007. Eligible participants comprised 455 adults who had joined the Northamptonshire smokingcessation programme during the period July to September 2006, and who had successfully quit at four weeks, as assessed by CO monitoring. ${ }^{5}$ Pregnant smokers wishing to quit are managed in a differently-configured programme and the study therefore excludes respondents in this category. 
Participants had consented to be followed up at one year, as part of routine monitoring of their current smoking status; they were contacted by telephone for this purpose in late 2007, up to three calls at differing times of the day being made to each participant, as required. During this call, scripted to ensure consistency, participants were requested to complete a written questionnaire, addressing their motivation and reasons for quitting. The 205 participants agreeing to this were sent a questionnaire with a postage-paid return envelope; in addition, unsolicited questionnaires were sent to the 112 participants with whom no telephone contact could be made, or for whom no record of a telephone number was available.

\section{Questionnaire Design}

The questionnaire administered to participants comprised two sections, one collecting personal details of the participant, their families and their domestic arrangements, and an analytical section addressing the reasons why individual smokers decided to stop smoking. The 23 questions in this section explored a range of health, social and economic factors, identified during a "brain-storming" session as potentially influencing an individual's decision to stop smoking. For each factor, the respondent was asked to indicate whether it had major, minor or zero influence on their decision to stop smoking. These factors were listed randomly, to avoid prejudicing the response, with open questions providing an opportunity for the respondents to include additional comments, explanations or clarifications. During the initial stages of questionnaire development, two pilot versions were trialled on small sample populations. Comments from respondents to the first pilot informed minor modifications to the terminology employed, leading to $100 \%$ satisfaction with the second pilot, which was then deployed as the definitive version.

\section{Questionnaire Response}

Of the 478 clients confirmed as four-week quitters and therefore qualifying for the study, 3 died before the 12-month review point and a further 30 were excluded for administrative reasons. Of the remaining 445 eligible clients 205 (46.0\%) agreed verbally during the 12-month telephone follow- 
up interview to participate in the study and were sent postage-paid questionnaires. Unsolicited questionnaires were also sent to the $112(25.1 \%)$ participants with whom no telephone contact could be made or for whom no record of a telephone number was available. Of the 317 questionnaires despatched, 103 completed questionnaires were received $(32.5 \%$ of the total sent, $50.0 \%$ of those consenting to receive one).

Disregarding the potential biasing effect of the unsolicited questionnaires, the response here is comparable with the $49 \%$ encountered in the most recent radon-related assessment, ${ }^{31}$ its content and nature reflecting many of the features, including prior contact, first-class postage out and postagepaid return, and overall length, acknowledged as enhancing questionnaire return. ${ }^{32}$

\section{Additional Data}

\section{Deprivation Index}

The Index of Multiple Deprivation (IMD) combines indicators covering a range of economic, social and housing issues into a single deprivation score for an area, allowing areas to be ranked relative to one another according to their level of deprivation. ${ }^{33}$ At its highest resolution, IMD is reported at Lower Layer Super Output Area (LSOA) level; each LSOA, of which there are 32,482 in England, contains around 1500 residents. Using postcodes or full addresses, respondents' places of residence were assigned to the appropriate LSOA, this being used to ascertain the corresponding IMD. Northamptonshire being relatively un-deprived, no respondent's place of residence returned an IMD greater than 47. The mean values of the IMD score for respondents was 17 (standard deviation 11) and respondents were therefore divided into two groups, depending on whether the IMD characterising their residence was $<16$ or $\geq 16$.

\section{Radon}

Using postcode of residence, arithmetic mean annual domestic radon concentration figures were assigned to each respondent using data from the 2002 Radon Atlas of England. ${ }^{34}$ Each respondent was then classified as living in an area of low, medium or high radon risk, depending on whether 
their home was in an area with $\leq 4.9 \%$, between $5 \%$ and $9.9 \%$, or $\geq 10 \%$ respectively of homes with radon concentrations above the UK Action Level of 200 Bq. $\mathrm{m}^{-3}$.

\section{Data Analysis}

Data from completed questionnaires were screened and cross-referenced with the mail-out database to record return rates, and entered into a bespoke database with double-entry validation, allowing comparison and further checks. Following data-cleaning to eradicate duplicate entries and to address queries arising from misinterpretation of written replies, responses to the reasons for quitting were ranked using a simple algorithm. Factors identified as having major/minor/zero influence on the decision to quit smoking were graded 3/2/1 respectively. Weighted average responses were generated for each of the 23 factors, using the relationship:

$$
W=\frac{\left.\left\{\left(N_{3} \times 3\right)+\left(N_{2} \times 2\right)+N_{1}\right)\right\}}{\left(N_{3}+N_{2}+N_{1}\right)}
$$

where $\mathrm{N}_{3}, \mathrm{~N}_{2}$ and $\mathrm{N}_{1}$ represent the number of major, minor and zero responses respectively. A significant proportion of respondents failed to respond meaningfully to one or more options, returning null rather than major/minor/zero responses; as these were discounted in generating weighted averages, the sum $\left(\mathrm{N}_{3}+\mathrm{N}_{2}+\mathrm{N}_{1}\right)$ does not always equal the total number of respondents.

Data were analysed using Microsoft Excel 2010 and IBM SPSS v.17. To explore the responses more comprehensively, filters were applied to characterise and compare the responses of sets of related population sub-groups. When comparing pairs of population sub-groups, the MannWhitney $U$ test ${ }^{35}$ was applied, with the Kruskal-Wallis test ${ }^{36}$ being used where it was necessary to compare three or more sub-groups.

\section{RESULTS}

\section{Demography}

There were no statistically significant differences between the sex ratios of the initial cohort of 482 clients and the 103 respondents returning questionnaires $\left(\chi^{2}=1.280, d f=1, p=0.258\right)$, although the 
questionnaire respondents were generally older than the population of quitters from which they were drawn (respondents $53.0 \pm 14.3$ years; all quitters $45.6 \pm 15.2$ years (mean \pm S.D.)) Population age distributions for the study and Northamptonshire at the 2001 Census $^{37}$ are oppositely skewed, skew parameters being 0.059 and -0.453 respectively, the difference between male and female study populations and the corresponding Northamptonshire populations being significant ( $p=0.07$ and 0.05 respectively). When respondents' partners and children are included, the study sample age distribution has statistically lower age profile then the general population. ${ }^{37}$ Figure $\mathbf{1}$ illustrates the difference in age distributions between the overall smoking cessation population and the questionnaire respondents $\left(\chi^{2}=20.061, d f=6, p=0.003\right)$.

Sixty-nine (67\%) respondents live with a partner/spouse, eight (8\%) share a home with parents or unrelated individuals and 26 (25\%) live alone. Twenty-nine (29\%) respondents live with a smoker. Thirty-four (33\%) respondents live with children and no household included more than three children. The mean age for children (defined by relationship rather than age) was $12.2 \pm 8.2$ years (mean \pm S.D.). Fourteen co-residing 'children' were aged 18 years or more, the oldest being aged 39 years. The children's age distribution in the study differs significantly from the Northamptonshire population $(p=<0.001)$.

Since radon levels are usually diminished in upper storeys, participants were asked to indicate their dwelling-type. The reported distribution is not significantly different $\left(\chi^{2}=0.91, p=0.46\right)$ from that of homes in England generally. ${ }^{38}$

Ninety-five (92\%) respondents identified themselves as 'White', two each (2\%) identifying themselves as 'Asian/British Asian', 'Black/Black British', Other (unspecified) and Not Disclosed. The ethnic composition in the study is not significantly different $\left(\chi^{2}>0.999, p=0.49\right)$ from that of the Northamptonshire population. Thirty six respondents declined to provide information on their education status, and of the remaining 67, 51 (76\%) had received no formal education beyond secondary school level. Thirty-nine ( $86 \%$ of those responding) had attained the UK General 
Certificate of Secondary Education, 14 (21\%) achieved UK Advanced Level, a further 14 (21\%) progressing to Diploma (9 (13\%)), Degree (4 (6\%)) or Higher Degree (1 (1\%)) qualifications. The distribution of educational attainment in the study is not significantly different from the population of Northamptonshire as a whole $\left(\chi^{2}>0.9999, p=0.52\right)$.

\section{Smoking Cessation}

Table 1 reports length of time (months) of the most recent quit period. Of 103 respondents, 68 confirmed that they were currently not smokers; 52 respondents remained tobacco-free after 12 months, with 16 admitting to a quit period less than 12 months, indicating temporary relapse since joining the cessation programme. The remaining 35 (60\% of whom were female) had relapsed. Quit period for the 68 confirmed non-smokers was $399 \pm 176$ days (mean \pm S.D.).

\section{Factors Influencing Smoking Cessation}

\section{General Observations}

Preliminary analysis of results from this study ${ }^{8}$ found significant differences in family size distribution between quitters and the UK population $(\alpha=0.05, p=0.011)$, quitters generally having larger families. Age distributions of quitters and their families show no significant difference from the Northamptonshire population $(\alpha=0.05, p=0.185)$. Quitters are more likely to have been in their current house for a shorter time than the national population $(\alpha=0.05, p=0.033)$, a finding possibly related to the respondents' age distribution. Relapsed smokers were more likely to have children over 18 at home $(\alpha=0.05, p=0.003)$; continuing quitters were more likely to have children under 18 at home $(\alpha=0.05, p=0.002)$, and were also more likely to be living with a partner or parent $(\alpha=0.05, p=0.046)$

Table 2 summarises the questionnaire data, consolidating responses to each of the 23 cessation factors, presenting the weighted sum and ranking of each factor, tabulated in order of ranking. For compatibility with more-focussed data presented subsequently, where only the five highest- and lowest-ranked factors are discussed, the boundaries of the sets of five highest- and lowest-ranked 
factors are indicated. The five highest-ranked factors included four health-related risks, those of developing bronchitis/emphysema, heart disease, lung-cancer and other cancers. The lowest ranked factor was pressure from work colleagues.

Table 3 reports the influencing factors in order of global ranking and maps the ranking of these subgroups against this ordering, while Table 4 summarises the outcomes of non-parametric statistical tests applied to the responses from these population sub-group sets. Results of these comparisons and the associated statistical tests are discussed in the following sections.

\section{Gender}

Males and females ranked common sets of four health-related factors among their five highest and five lowest ranked factors, males matching all five global factors in each case. Risk of developing bronchitis, lung-cancer and heart disease was ranked most highly by both genders, with concerns over other cancers and NRT availability both falling within the five highest ranked influences. Both genders ranked pregnancy and awareness of the hazards of radon and asbestos as of minimal influence. The only statistically significant difference relates to the prospect of developing bronchitis, which males regarded as of more concern than did females $(U=812, p=0.037)$.

\section{Age and Child-Bearing}

To identify differences in attitude between women of child-bearing age and those whose families are completed, responses of females aged $<40$ years and $\geq 40$ years were analysed. Both groups matched four out of the five highest and three out of the five lowest global responses, the principal, and most significant, difference in emphasis being that while women aged $<40$ years ranked pregnancy (globally $\left.20^{\text {th }}\right)$ in $8^{\text {th }}$ place, their older counterparts placed this $23^{\text {rd }}(U=93, p=0.007)$. The younger group regarded both access to NRT $(U=142, p=0.014)$ and legislation banning smoking in public places statistically more significant $(U=102, p=0.029)$ than did their elders. 


\section{Smoking Status}

Relapsed smokers and continuing non-smokers ranked common sets of four health-related factors among their five highest and five lowest ranked factors, smokers matching all five global factors in each case. Smokers ranked cost of cigarettes in $5^{\text {th }}$ place, non-smokers regarding this as less significant $\left(8^{\text {th }}\right)$. Smokers regarded availability of NRT as marginally more significant $\left(4^{\text {th }}\right)$ than non-smokers $\left(5^{\text {th }}\right)$. Pregnancy (globally $20^{\text {th }}$ ) was ranked $19^{\text {th }}$ and $22^{\text {nd }}$ by non-smokers and smokers respectively, while non-smokers ranked knowledge of the risks of asbestos $\left(22^{\text {nd }}\right)$ and radon $\left(23^{\text {rd }}\right)$ marginally less significant than did smokers $\left(20^{\text {th }}\right.$ and $\left.19^{\text {th }}\right)$. Overall, no less than 12 of the 23 potential influences were identified as being statistically significant in the decision to stop smoking. These included awareness of addiction $(U=582 . p=0.016)$, access to NRT $(U=648 . p=0.015)$, the effect of smoke on other people $(U=858 . p=0.027)$ and adult family members $(U=387$. $p=0.009)$, the cost of cigarettes $(U=.571 p=0.002)$, the prospect of developing non-lung cancers $(U=554 . p=0.010)$, media $(U=439 \cdot p=0.011)$ and government $(U=472 \cdot p=0.003)$ campaigns, legislation $(U=399 . p=0.002)$, peer pressure $(U=400 . p=0.010)$ and knowledge of the potential harmful effects of radon $(U=416 . p=0.006)$ and asbestos $(U=408 \cdot p=0.006)$.

\section{Occupancy}

Respondents living with a spouse matched all five highest globally ranked factors. Those living alone matched four, elevating the risk of developing other cancers (globally $4^{\text {th }}$ ) to $1^{\text {st }}$, at the expense of access to prescription NRT, (globally $5^{\text {th }}$, demoted to $8^{\text {th }}$ ). Respondents living alone ranked cost of cigarettes (globally $6^{\text {th }}$ ) as the second most significant factor. People living alone or with a spouse matched all five global lowest rank factors, albeit with minor changes in emphasis, while those living with a partner ranked pregnancy significantly higher $\left(15^{\text {th }}\right)$ than did the population at large $\left(20^{\text {th }}\right)$, or those living with a spouse $\left(21^{\text {st }}\right)$. None of these differences were found to be statistically significant. 


\section{Children in the Home}

While the 69 respondents without children under 17 in their home matched the five highest and five lowest globally ranked factors the 34 respondents with children under the age of 17 in their homes showed the greatest divergence from the global population of any group selected by filtering, ranking the effect of their smoke on children in the family (globally $9^{\text {th }}$ ) in $5^{\text {th }}$ place, pressure to stop smoking from children in the family (globally $10^{\text {th }}$ ) in $6^{\text {th }}$ place, and pregnancy (globally $20^{\text {th }}$ ) in $15^{\text {th }}$ place. The effect of smoke on other people was ranked $8^{\text {th }}$, precisely reflecting the global response. Recently diagnosed illness $(U=538, p=0.040)$ and legislation on public smoking ( $U=518, p=0.023$ were both statistically significant for those with children under 17 in the home. Somewhat surprisingly, pregnancy $(U=401, p=0.007)$ and the effects of smoke on children ( $U=404, p=0.007)$ were statistically more significant factors for respondents without children under 17 than for respondents with children in this age range.

\section{Deprivation}

Respondents living in areas of both lower (IMD $<16$ ) and higher (IMD $>=16$ ) deprivation indicated common sets of four highest- and lowest-ranked factors, with minor differences in ordering. Health factors consistently occupied the top four positions, with both groups placing pregnancy and awareness of radon and asbestos in the lowest five positions. There was no significant difference $(p=0.45)$ between the distribution of relapsed smokers and continuing quitters across the range of IMDs included in the study. Three significant differences were apparent, with another member of the family becoming ill $(U=564, p=0.050)$, pregnancy $(U=459, p=0.024)$ and effect of smoke on other adult family $(U=532, p=0.028)$ being all more important to those living in areas of low deprivation.

\section{Radon}

Respondents living in low-, medium- and high-risk radon areas ranked common sets of four healthrelated factors among their five highest and five lowest ranked factors, residents of low-radon areas 
matching all five lowest factors of the global response. Residents of high-radon areas exhibited the greatest anomaly, ranking realisation that they were addicted in $3^{\text {rd }}$ place (globally $7^{\text {th }}$ ) and the prospect of developing other cancers (globally $4^{\text {th }}$ ) in $8^{\text {th }}$ place. All groups ranked awareness of radon as a health risk in $22^{\text {nd }}$ place, identical to the global ranking. There were no statistically significant differences between the responses from residents low, medium or high radon risk areas.

Although the presence of radon in the home is a factor taken into account in assessing the fitness of a home for habitation, ${ }^{39}$ and by implication in the derivation of the IMD, no correlation was identified between IMD and either arithmetic mean radon concentration $(r=0.036, p=0.719)$ or radon risk level ( $r=0.040, p=0.692)$ for postcode of residence.

\section{Living with a Smoker}

All respondents matched four of the first five global responses, those living with a smoker ranking cost of cigarettes (globally $6^{\text {th }}$ ) in $11^{\text {th }}$ place and medical advice (globally $5^{\text {th }}$ ) in $11^{\text {th }}$ place. Those living with a smoker matched the lowest five categories of the global response, while the remainder of the population identified support group membership (globally $19^{\text {th }}$ ) as their $17^{\text {th }}$ most significant effect. The cost of cigarettes is significantly more important for respondents living with a smoker $(U=645, p=0.050)$, while recently diagnosed illness $(U=408, p=0.019)$ and medical advice $(U=526, p=0.030)$ are more important to those not living with a smoker.

\section{DISCUSSION}

\section{Personal Health Issues}

The risks of developing respiratory $\left(1^{\text {st }}\right)$, coronary/cardiac $\left(3^{\text {rd }}\right)$ or cancerous $\left(2^{\text {nd }}\right.$ and $\left.4^{\text {th }}\right)$ conditions emerge as the most generally significant influences on the decision to cease smoking Women of child-bearing age, assumed here as $\leq 40$ years, ranked pregnancy $8^{\text {th }}$ in influence, compared with $23^{\text {rd }}$ reported by women aged $>40,21^{\text {st }}$ among women globally and $20^{\text {th }}$ by respondents generally. Similarly, respondents with children aged $<17$ years clearly regard pregnancy as a more significant factor $\left(15^{\text {th }}\right)$ than do respondents with no children in this age range $\left(23^{\text {rd }}\right)$. Overall, while medical 
advice $\left(11^{\text {th }}\right)$ was as a moderately significant factor, albeit with rather wide variability amongst the various filter groups, respondents did not generally regard a recently diagnosed illness, either personal $\left(16^{\text {th }}\right)$ or of another family member $\left(15^{\text {th }}\right)$, as pressing reasons to quit smoking.

\section{Consideration for Others}

Consideration of the effects of smoking on other people is complex, with differing emphasis placed on the effects of smoking on others generally, on co-resident children and on co-resident adults. Where others generally are concerned, responses range from $4^{\text {th }}$ (residents of medium-radon areas) to $10^{\text {th }}$ (females aged $\leq 40$, respondents living with a partner and residents of high-radon areas), globally $8^{\text {th }}$.

Within the family, this concern is equally significant, the effect of smoke on children and adult family members having global rankings of $9^{\text {th }}$ and $12^{\text {th }}$ respectively. Again, significant differences emerge, most notably that whereas respondents with children aged $<17$ years in their home ranked the effects of their smoke in $5^{\text {th }}$ place, those without children aged $\geq 17$ years ranked it $13^{\text {th }}$. Respondents living with a partner, with a spouse and alone ranked the effect of their smoke on children at $10^{\text {th }}, 7^{\text {th }}$ and $10^{\text {th }}$ place respectively. In contrast, most respondents ranked the effect of their smoke on adults in the home between $9^{\text {th }}$ (respondents living with a partner or living in highIMD areas) and $16^{\text {th }}$ place (respondents living in high-radon areas).

\section{Response to Others}

Pressure from children in the family to stop smoking ranked $10^{\text {th }}$ globally, with comparable pressure from other adults in the family ranking $13^{\text {th }}$ place. Respondents with children aged $<17$ years ranked pressure from children as $6^{\text {th }}$, while those with children aged $\geq 17$ years ranked it $10^{\text {th }}$, possible because children in that age range are likely to be smokers themselves. Respondents living with a spouse ranked pressure from children somewhat higher $\left(6^{\text {th }}\right)$ than did respondents living with a non-spousal partner $\left(11^{\text {th }}\right)$ while respondents living alone ranked this influence, somewhat surprisingly, in $12^{\text {th }}$ place. 
Pressure from work colleagues appears largely ineffectual, with global ranking of $23^{\text {rd }}$, with minimal variability among the different filter groups.

\section{Environmental Hazards}

With a global ranking of $22^{\text {nd }}$, it is evident that, although all respondents lived in Radon-Affected Areas, knowledge of radon did not influence ongoing quitters in their initial decision to stop smoking, although residents of low-radon areas ranked this factor slightly less highly $\left(23^{\text {rd }}\right)$ than did all other respondents $\left(21^{\text {st }}\right)$, while smokers demonstrated a slightly higher $\left(19^{\text {th }}\right)$ perception of the risk of radon when making their decision to stop smoking. Note, however, that while identifying a gap in knowledge of radon risks represents a possibility for intervention, it will not necessarily be effective, and would need further evaluation in controlled conditions.

A similar picture emerges for asbestos risk (global rank $20^{\text {th }}$ ), included to ensure that radon was not identified as the sole, and thus significant, environmental factor in the study.

\section{Social and Economic Factors}

Access to prescription NRT, globally ranked $5^{\text {th }}$, was similarly ranked by respondents remaining quit after one year (non smokers). Smokers ranked NRT access as $4^{\text {th }}$, while females ranked it as being of lower influence $\left(6^{\text {th }}\right)$ than did males $\left(4^{\text {th }}\right)$. This may provide indication that using NRT as a quitting aid results in longer-term abstinence than achieved by attempting to quit without it.

The cost of purchasing cigarettes (globally $6^{\text {th }}$ ) ranked more highly among relapsed smokers $\left(5^{\text {th }}\right)$ than continuing non-smokers $\left(8^{\text {th }}\right)$, suggesting either that those who relapse worry about cost, but do nothing about it, or that continuing non-smokers rank another factor (possibly personal health) higher. Cost appears more of a significant influence on respondents living alone $\left(2^{\text {nd }}\right)$, a somewhat surprising finding given that the latter do not have financial responsibilities of partners and children. With $60 \%$ of this category living in low deprivation areas (IMD $<16$ ), a link with income is 
probably unlikely; this finding may reflect awareness on the part of the 'better-off' that disposable income not spent on smoking can be usefully applied to other life-style areas.

Finally, public issues and campaigns appear to have relatively minor influence. Legislation (ranked $\left.14^{\text {th }}\right)$, Government stop-smoking campaigns $\left(17^{\text {th }}\right)$, media advertising campaigns $\left(18^{\text {th }}\right)$ and support group membership $\left(19^{\text {th }}\right)$ all appear in the bottom half of the table and all show minimal variability across the various filter groups.

\section{CONCLUSIONS}

A major conclusion from this analysis is that 'self interest' is a leading factor in the decision to quit smoking. Individuals are primarily concerned about the risks to their own personal health, and generally regard the effect of their continuing to smoke on children or other adults in the family as less significant (these were ranked $9^{\text {th }}$ and $\left.12^{\text {th }}\right)$. Furthermore, availability of prescription NRT $\left(5^{\text {th }}\right)$ notwithstanding, individuals regard the efforts of society, including Government-sponsored smoking-cessation services and widespread media campaigns, as less important factors in their decision $\left(17^{\text {th }}\right.$ and $\left.18^{\text {th }}\right)$. However, whilst not identified as leading factors in the decision to stop smoking, media campaigns may actually be highly successful because they inform people about the risk of developing lung disease, heart disease and cancer, which in turn, become the major catalyst for people to change their behaviour $\left(1^{\text {st }}, 2^{\text {nd }}\right.$ and $\left.3^{\text {rd }}\right)$.

Unsurprisingly, the results suggest that knowledge of the risk of developing respiratory disease, lung-cancer or cardiovascular disease provides the greatest motivating factors when a smoker is making the decision to quit. However, as now confirmed, knowledge that exposure to radon in the home increases the risk of developing tobacco-related illness is among the lowest ranked $\left(22^{\text {nd }}\right)$ reasons when deciding to quit smoking. The low ranking for 'pregnancy' can be explained by the fact that the study contained no pregnant smokers, as noted earlier, and only women of childbearing age are likely to regard this factor as significant. 
These findings provide further confirmation that targeted interventions for high-risk groups remain priority areas. Health professionals and smoking-cessation advisors in acute, primary, secondary and community care settings should target interventions that inform smokers of the debilitating effects of tobacco-induced diseases.

To date there have been no active campaigns to inform smokers who live in Radon-Affected Areas that they are at increased risk of developing lung-cancer as a direct result of exposure to radon and smoking in combination, and there has therefore been no targeted emphasis on the desirability of quitting smoking among these groups. The present study, although preliminary in its scope, demonstrates clearly that the key influences on quitting are personal health issues, but that radon, and its associated health risk, is not considered significant. This suggests that significant opportunities exist to develop and implement specialised smoking-cessation campaigns directed specifically at smokers living in Radon-Affected Areas, of which Northamptonshire is a typical example.

These findings are consistent with wider health priorities set by the World Health Organization (WHO) and UK Department of Health. The WHO has made reducing the incidence and prevalence of tobacco related diseases a priority, ${ }^{40}$ and the UK Government has initiated a health inequalities reduction programme, aiming to close the health status gap between the most and least advantaged sectors of society. ${ }^{41}$ One of the specified measures for reducing health inequalities is reduced smoking uptake and increased smoking-cessation among disadvantaged groups. Our recommendation for a targeted campaign may assist in achieving this specific policy target.

Finally, governments world-wide have moral and ethical obligations to provide citizens with opportunities to achieve good health, including provision of information on avoiding ill-health. People should never be coerced to act on this information, but they should be encouraged to make an informed choice. It would be unethical for any government to withhold information that can assist people in making healthy choices, and it would be immoral to deny individuals this basic 
right to make an informed choice about their health. We suggest that residents of Radon-Affected Areas should receive more information about the synergistic effect of tobacco smoking and exposure to domestic radon. 


\section{ACKNOWLEDGEMENTS}

General: We are grateful to the Referees for their helpful and constructive comments on the original manuscript.

Funding: The authors acknowledge financial support from the NHS Trent Research and Development Support Unit via funding of a Designated Research Team.

Ethics approval: This study was conducted with approval of the NHS Nottingham 2 Research Ethics Committee, Reference Number 07/H0408/85, submitted in June 2007, approved August 2007, under the title The decision to stop smoking - what factors are taken into account? The study was carried out by written questionnaire, and participants confirmed their informed consent by agreeing to receive a questionnaire and by returning completed questionnaires by post.

\section{Competing interests: None.}

Contributors: All authors took part in the initial definition and planning of the study. KT and GS managed the questionnaire distribution and collection, and CJGK oversaw the data extraction process. CJGK and JC performed the data analysis, with JC providing significant statistical input. KT produced a first draft of the text, ME generated the conclusions and CJGK processed the final manuscript. AD, SR and PP provided managerial and organisational input throughout the project. All authors contributed to the final revision of the manuscript and its preparation for publication.

Provenance and peer review: Not commissioned; externally peer reviewed. 


\section{REFERENCES}

$1 \quad$ Parrott S, Godfrey C. Economics of smoking cessation. Br Med J 2007;328:947-949

2 Twigg L, Moon G, Szatkowski L, Iggulden P. Smoking cessation in England: intentionality, anticipated ease of quitting and advice provision. Soc Sci Med 2009;68:610-619

3 Robinson S, Harris H. Smoking and Drinking among Adults, 2009 - A report on the 2009 General Lifestyle Survey. Cardiff: Office for National Statistics; 2011

4 HM Government. Smoking Kills: a White Paper on Tobacco. London: The Stationery Office; 1998, CM4177

5 Middleton ET, Morice AH. Breath carbon monoxide as an indication of smoking habit. Chest 2000;117:758-763

6 Twigg L, Moon G, Szatkowski L, Iggulden P. Smoking Cessation in England: Intentionality, Anticipated Ease of Quitting and Advice Provision. Soc Sci Med 2009;68:610-9.

7 Groves-Kirkby CJ, Denman AR, Timson K, Shield G, Phillips P, Rogers S. Radon, tobacco and lung-cancer-the significance of smoking cessation programmes. Health Protection Matters 2008;12:40-44

8 Denman AR, Timson K, Shield G, Groves-Kirkby CJ, Rogers S, Campbell JA et al. Local health campaigns to reduce lung-cancers induced by radon and smoking - who responds? Health Policy 2009;93:201-2006

9 Bauld L, Bell K, Lucy McCullough L, Richardson L, Greaves L. The effectiveness of NHS smoking cessation services: a systematic review. J Public Health 2010;32:71-82.

10 Darby S, Hill D, Doll R. Radon - a likely carcinogen at all exposures. Ann Oncol 2001;12:1341-1351

11 BEIR VI (Committee on Health Risks of Exposure to Radon). Health Risks of Exposure to Radon. Washington DC: National Academy Press; 1999, ISBN:0-309-05645-4

12 Darby S, Hill DC, Auvinen A, Barros-Dios JM, Baysson H, Bochicchio F et al. Radon in homes and risk of lung-cancer: collaborative analysis of individual data from 13 European case-control studies. Br Med J 2005;330:223-228

13 Gray A, Read S, McGale P, Darby S. Lung-cancer deaths from indoor radon and the cost effectiveness and potential of policies to reduce them. Br Med J 2009;338:a3110

14 O'Riordan M. Human Exposure to Radon in Homes: Recommendations for the Practical Application of the Board's Statement. Documents of the NRPB 1990;1:17-32 
15 Groves-Kirkby CJ, Denman AR, Phillips PS, Tornberg R, Woolridge A. Domestic radon remediation of U.K. dwellings by sub-slab depressurisation: evidence for a baseline contribution from constructional materials. Environment International 2008; 34:428-436

16 Rees DM, Bradley EJ, Green BMR. Radon in Homes in England and Wales: 2010 Data. Chilton, Berks: Health Protection Agency; 2011, Report No. HPA-CRCE-015, ISBN:978-085951-688-4

17 Miles JCH, Green BMR, Lomas PR. Radon-Affected Areas: Derbyshire, Northamptonshire and Somerset. Documents of the NRPB 1992;3:19-28

18 Coskeran T, Denman AR, Phillips PS, Tornberg R. A cost-effectiveness analysis of domestic radon remediation in four primary care trusts located in Northamptonshire, UK. Health Policy 2005;71:43-56

19 Denman AR, Barker SP, Parkinson S, Phillips PS. The health benefits and cost effectiveness of the radon mitigation programme in NHS properties in Northamptonshire. J Radiol Prot $1997 ; 17: 253-259$

20 Denman AR, Phillips PS. The cost-effectiveness of radon mitigation in schools in Northamptonshire. J Radiol Prot 1998;18:203-208

21 Denman AR, Phillips PS. Workplace radon in Northamptonshire. Environmental Management and Health 1998;9:194-199

22 Denman AR, Phillips PS. A review of the cost-effectiveness of radon mitigation in domestic properties in Northamptonshire. J Radiol Prot 1998;18:119-124

23 Kennedy CA, Gray AM, Denman AR, Phillips PS. A cost effectiveness analysis of a residential radon remediation programme in the United Kingdom. Br J Cancer 1999;81:1243-1247

24 Denman AR, Phillips PS, Tornberg R. A comparison of the costs and benefits of radon remediation programmes in new and existing houses in Northamptonshire. J Environ Manage 2000;59:21-30

25 Phillips PS, Fraser JD, Denman AR. Effectiveness of secondary radon protection in Northamptonshire homes. Environmental Management and Health 2000;11:337-351

26 Coskeran T, Denman AR, Phillips PS. The costs of radon mitigation in domestic properties. Health Policy 2001;57:97-109

27 Coskeran T, Denman AR, Phillips PS, Gillmore GK. A critical comparison of domestic radon remediation programmes in three counties of England. J Environ Radioact 2002;62:129-144 
28 Denman AR, Phillips PS, Tornberg R. Comparing the value of remediation programmes in Radon-Affected Areas : a case study in hospitals, schools and homes in Northamptonshire, UK. Fresenius Environmental Bulletin 2000;9:435-442

29 Denman AR, Groves-Kirkby CJ, Phillips PS, Tornberg R. Using the European Community Radon Software to estimate the individual health benefits of a domestic radon remediation programme. J Radiol Prot 2004;24:83-89

30 Denman AR, Phillips PS, Tornberg R, Groves-Kirkby CJ. Analysis of the individual health benefits accruing from a domestic radon remediation programme. $J$ Environ Radioact $2005 ; 79: 7-23$

31 Chow Y, Meara J, Green BMR, Zhang W. Evaluation and equity audit of the domestic radon programme in England. Health Policy 2011; 102:81-88

32 Edwards P, Roberts I, Clarke M, DiGuiseppi C, Pratap S, Wentz R, Kwan I. Increasing response rates to postal questionnaires: systematic review. BMJ 2002;324:1183-1192

33 McLennan D, Barnes H, Noble M, Davies J, Garratt E. The English Indices of Deprivation 2010. London: Communities and Local Government; 2011, ISBN:978-1-4098-2922-5

34 Green BMR, Miles J, Bradley EJ, Rees DM. Radon Atlas of England and Wales. Chilton, Berks: Health Protection Agency; 2002, Report No. HPA-W26, ISBN:0-85951-497-8

35 Mann HB, Whitney DR. On a test of whether one of two random variables is stochastically larger than the other. Ann Math Statistic 1947;18:50-60.

36 Kruskal WH, Wallis WA. J Amer Statistic Assoc 1952:47: 583-621.

37 Census 2001: Key Statistics for Local Authorities in England and Wales. London: The Stationery Office; 2003, ISBN:0-11-621643-3

38 Hewton J, Humphrey A. Housing in England 2003/04. London: Department for Communities and Local Government; 2006, Report No. 06 HC 03868

39 Office of the Deputy Prime Minister. Housing Health and Safety Rating System: Guidance (Version 2). London: HMSO; 2004, ISBN 1-85112-752-6

40 World Health Organisation. WHO Report on the Global Tobacco Epidemic, 2008: the MPOWER Package. Geneva: World Health Organisation; 2008, ISBN:978-92-4-159628-2

41 Department of Health. Tackling Health Inequalities: a Programme for Action. London: Department of Health; 2003 


\section{FIGURES}

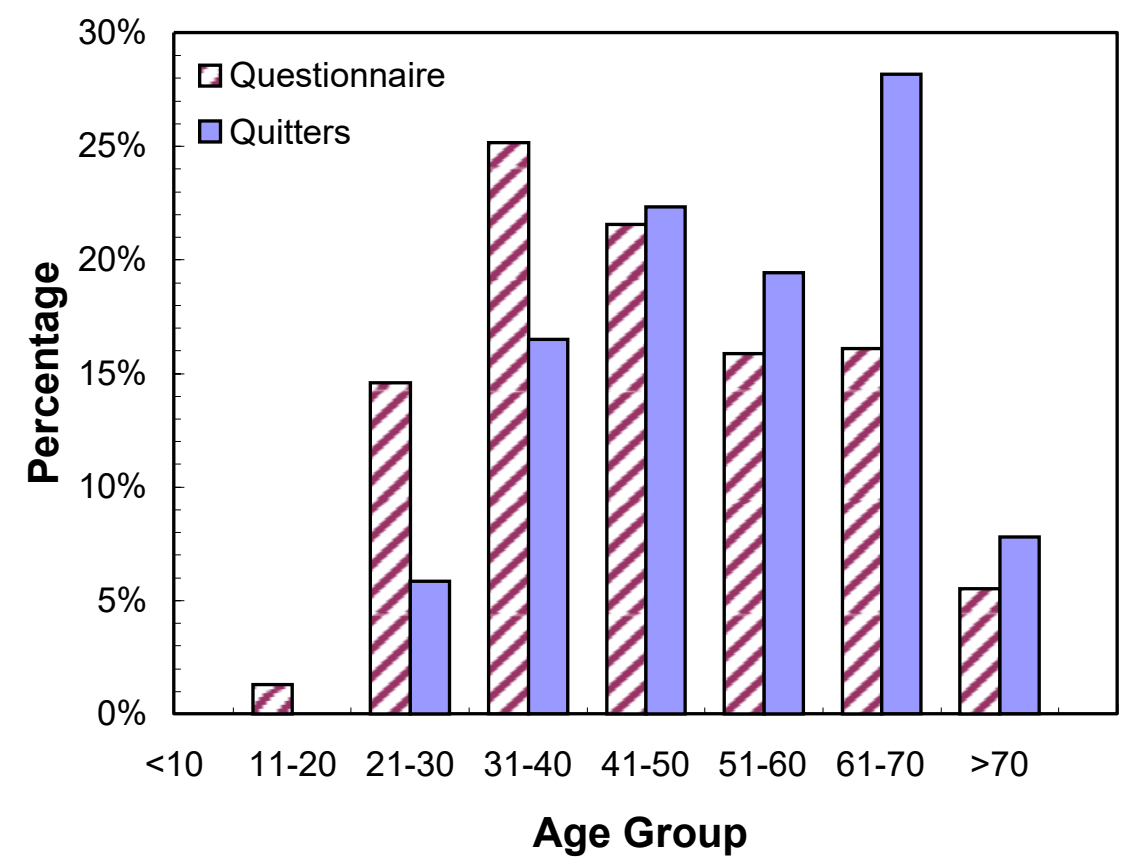

Figure 1: Age distributions of Smoking Cessation Population and Questionnaire Respondents 


\section{TABLES}

Table 1: Length of most recent quit period

\begin{tabular}{lc}
\hline Quit Period [Months] & Frequency \\
\hline Current Smoker & 35 \\
$0-3$ & 6 \\
$3-6$ & 6 \\
$6-9$ & 1 \\
$9-12$ & 3 \\
$12-15$ & 29 \\
$15-18$ & 18 \\
$18-21$ & 2 \\
$21-24$ & 1 \\
$>24$ & 2 \\
\hline
\end{tabular}


Table 2: Full Population Ranking of Responses

\begin{tabular}{|c|c|c|c|c|c|c|}
\hline \multirow{2}{*}{ Cessation Factor } & \multicolumn{4}{|c|}{ Influence } & \multirow{2}{*}{$\begin{array}{l}\text { Weighted } \\
\text { Average }\end{array}$} & \multirow{2}{*}{$\begin{array}{c}\text { Global } \\
\text { Rank }\end{array}$} \\
\hline & Major & Minor & Zero & Null & & \\
\hline Prospect of developing bronchitis etc & 59 & 27 & 5 & 12 & 2.593 & 1 \\
\hline Prospect of developing lung-cancer & 52 & 29 & 5 & 17 & 2.547 & 2 \\
\hline $\begin{array}{l}\text { Prospect of developing heart disease or risk of heart } \\
\text { attack }\end{array}$ & 55 & 24 & 8 & 16 & 2.540 & 3 \\
\hline Prospect of developing other cancers & 46 & 31 & 7 & 19 & 2.464 & 4 \\
\hline Access to prescription NRT & 54 & 17 & 20 & 12 & 2.374 & 5 \\
\hline Cost of cigarettes & 44 & 26 & 20 & 13 & 2.267 & 6 \\
\hline Realising I am addicted & 38 & 31 & 17 & 17 & 2.244 & 7 \\
\hline Effect of my smoke on other people & 41 & 41 & 19 & 2 & 2.218 & 8 \\
\hline Effect of my smoke on children in the family & 33 & 15 & 24 & 31 & 2.125 & 9 \\
\hline Pressure to stop smoking from children in the family & 33 & 22 & 28 & 20 & 2.060 & 10 \\
\hline Medical advice & 33 & 24 & 28 & 18 & 2.059 & 11 \\
\hline Effect of my smoke on other adult family members & 25 & 25 & 27 & 26 & 1.974 & 12 \\
\hline $\begin{array}{l}\text { Pressure to stop smoking from other adult family } \\
\text { members }\end{array}$ & 26 & 23 & 32 & 22 & 1.926 & 13 \\
\hline Law preventing smoking in public places & 20 & 17 & 41 & 25 & 1.731 & 14 \\
\hline $\begin{array}{l}\text { Another family member became ill as a } \\
\text { consequence of smoking }\end{array}$ & 20 & 16 & 41 & 26 & 1.727 & 15 \\
\hline Recently diagnosed illness & 19 & 13 & 47 & 24 & 1.646 & 16 \\
\hline Government stop-smoking campaign & 10 & 26 & 46 & 21 & 1.561 & 17 \\
\hline $\mathrm{TV}$, radio, newspaper or magazine advertisement & 8 & 20 & 49 & 26 & 1.468 & 18 \\
\hline Member of support group & 12 & 10 & 51 & 30 & 1.466 & 19 \\
\hline Pregnancy & 9 & 6 & 54 & 34 & 1.348 & 20 \\
\hline Knowledge that exposure to asbestos increases risk & 6 & 12 & 56 & 29 & 1.324 & 21 \\
\hline Knowledge that radon gas in the home increases risk & 6 & 10 & 58 & 29 & 1.297 & 22 \\
\hline Pressure to stop from work colleagues & 3 & 15 & 55 & 30 & 1.288 & 23 \\
\hline
\end{tabular}


Table 3: Comparison of Sub-Group Rankings: Weighted Responses

\begin{tabular}{|c|c|c|c|c|c|c|c|c|c|c|c|c|c|c|c|c|c|c|c|}
\hline \multirow[t]{2}{*}{ Rank } & \multirow[t]{2}{*}{ Influence } & \multicolumn{2}{|c|}{ Gender } & \multicolumn{2}{|c|}{ Female Age } & \multicolumn{2}{|c|}{ Smoking Status } & \multicolumn{3}{|c|}{ Domestic Relationship } & \multicolumn{2}{|c|}{$\begin{array}{c}\text { Children }<17 \text { in } \\
\text { Household }\end{array}$} & \multicolumn{2}{|c|}{ Deprivation } & \multicolumn{3}{|c|}{ Radon Risk } & \multicolumn{2}{|c|}{$\begin{array}{l}\text { Live with } \\
\text { smoker }\end{array}$} \\
\hline & & Male & Female & $<40$ & $>=40$ & $\begin{array}{l}\text { Non- } \\
\text { Smoker }\end{array}$ & Smoker & $\begin{array}{c}\text { Live } \\
\text { with a } \\
\text { Partner }\end{array}$ & $\begin{array}{c}\text { Live } \\
\text { with a } \\
\text { Spouse }\end{array}$ & $\begin{array}{l}\text { Live } \\
\text { Alone }\end{array}$ & Yes & No & $<16$ & $>=16$ & $\begin{array}{l}\text { Low } \\
(0- \\
4.9 \%)\end{array}$ & $\begin{array}{l}\text { Med. } \\
(5.0- \\
9.9 \%)\end{array}$ & $\begin{array}{c}\text { High } \\
(10.0- \\
29.9 \%)\end{array}$ & Yes & No \\
\hline & Sample Size & 47 & 56 & 12 & 41 & 68 & 35 & 22 & 47 & 26 & 34 & 69 & 55 & 48 & 85 & 13 & 5 & 29 & 74 \\
\hline 1 & Prospect of developing bronchitis etc & 1 & 3 & 1 & 2 & 1 & 1 & 4 & 1 & 1 & 1 & 1 & 1 & 3 & 1 & 1 & 1 & 1 & 1 \\
\hline 2 & Prospect of developing lung-cancer & 3 & 2 & 2 & 4 & 3 & 2 & 3 & 2 & 4 & 3 & 2 & 2 & 2 & 2 & 5 & 4 & 2 & 2 \\
\hline 3 & $\begin{array}{l}\text { Prospect of developing heart disease } \\
\text { or risk of heart attack }\end{array}$ & 2 & 1 & 4 & 3 & 2 & 6 & 2 & 3 & 5 & 2 & 3 & 3 & 1 & 3 & 2 & 5 & 4 & 3 \\
\hline 4 & Prospect of developing other cancers & 5 & 4 & 3 & 5 & 4 & 3 & 1 & 4 & 7 & 4 & 5 & 4 & 4 & 4 & 6 & 8 & 3 & 4 \\
\hline 5 & Access to prescription NRT & 4 & 6 & 9 & 1 & 5 & 4 & 8 & 5 & 3 & 9 & 4 & 5 & 6 & 5 & 3 & 2 & 6 & 5 \\
\hline 6 & Cost of cigarettes & 6 & 8 & 5 & 6 & 8 & 5 & 5 & 9 & 2 & 7 & 6 & 8 & 5 & 6 & 9 & 6 & 11 & 6 \\
\hline 7 & Realising I am addicted & 8 & 5 & 13 & 8 & 6 & 7 & 6 & 8 & 8 & 10 & 7 & 7 & 7 & 7 & 7 & 3 & 7 & 7 \\
\hline 8 & Effect of my smoke on other people & 7 & 7 & 10 & 7 & 7 & 8 & 10 & 7 & 6 & 8 & 8 & 6 & 8 & 8 & 4 & 10 & 8 & 8 \\
\hline 9 & $\begin{array}{l}\text { Effect of my smoke on children in the } \\
\text { family }\end{array}$ & 9 & 13 & 6 & 9 & 10 & 9 & 7 & 10 & 10 & 5 & 13 & 9 & 11 & 10 & 8 & 11 & 9 & 9 \\
\hline 10 & $\begin{array}{l}\text { Pressure to stop smoking from } \\
\text { shildren in the family }\end{array}$ & 11 & 11 & 15 & 10 & 11 & 11 & 11 & 6 & 12 & 6 & 10 & 10 & 12 & 9 & 10 & 15 & 10 & 10 \\
\hline 11 & Medical advice & 10 & 9 & 7 & 11 & 9 & 13 & 14 & 11 & 9 & 13 & 9 & 11 & 10 & 11 & 11 & 7 & 5 & 13 \\
\hline 12 & $\begin{array}{l}\text { Effect of my smoke on other adult } \\
\text { family members }\end{array}$ & 12 & 10 & 11 & 13 & 13 & 10 & 9 & 13 & 11 & 12 & 11 & 13 & 9 & 12 & 13 & 16 & 12 & 12 \\
\hline 13 & $\begin{array}{l}\text { Pressure to stop smoking from other } \\
\text { adult family members }\end{array}$ & 13 & 12 & 12 & 14 & 12 & 14 & 13 & 12 & 15 & 11 & 14 & 12 & 15 & 13 & 12 & 20 & 14 & 11 \\
\hline 14 & $\begin{array}{l}\text { Law preventing smoking in public } \\
\text { slaces }\end{array}$ & 15 & 15 & 20 & 12 & 16 & 12 & 17 & 14 & 14 & 17 & 12 & 14 & 14 & 14 & 16 & 12 & 15 & 15 \\
\hline 15 & $\begin{array}{l}\text { Another family member became ill as } \\
\text { a consequence of smoking }\end{array}$ & 14 & 16 & 14 & 16 & 14 & 16 & 12 & 16 & 17 & 14 & 17 & 15 & 13 & 15 & 14 & 18 & 17 & 14 \\
\hline 16 & Recently diagnosed illness & 17 & 14 & 19 & 18 & 15 & 18 & 23 & 15 & 13 & 20 & 15 & 16 & 16 & 16 & 20 & 9 & 13 & 16 \\
\hline 17 & Government stop-smoking campaign & 16 & 17 & 16 & 15 & 18 & 15 & 18 & 18 & 16 & 18 & 16 & 17 & 17 & 17 & 18 & 14 & 16 & 18 \\
\hline 18 & $\Gamma \mathrm{V} /$ radio/newspaper/magazine advert. & 19 & 19 & 17 & 19 & 20 & 17 & 19 & 19 & 18 & 19 & 18 & 18 & 19 & 18 & 17 & 17 & 18 & 19 \\
\hline 19 & Member of support group & 18 & 18 & 23 & 17 & 17 & 23 & 16 & 17 & 23 & 16 & 19 & 19 & 18 & 20 & 15 & 13 & 21 & 17 \\
\hline 20 & Pregnancy & 20 & 21 & 8 & 23 & 19 & 22 & 15 & 21 & 20 & 15 & 23 & 22 & 20 & 21 & 19 & 19 & 23 & 20 \\
\hline 21 & $\begin{array}{l}\text { Knowledge that exposure to asbestos } \\
\text { increases risk }\end{array}$ & 23 & 20 & 22 & 22 & 22 & 20 & 22 & 20 & 19 & 21 & 21 & 20 & 22 & 19 & 23 & 23 & 19 & 21 \\
\hline 22 & $\begin{array}{l}\text { Knowledge that radon gas in the } \\
\text { tome increases risk }\end{array}$ & 22 & 23 & 21 & 20 & 23 & 19 & 20 & 23 & 22 & 22 & 22 & 23 & 21 & 22 & 22 & 22 & 20 & 23 \\
\hline 23 & Pressure to stop from work colleagues & 21 & 22 & 18 & 21 & 21 & 21 & 21 & 22 & 21 & 23 & 20 & 21 & 23 & 23 & 21 & 21 & 22 & 22 \\
\hline
\end{tabular}


Table 4: Comparison of Sub-Populations: Results of Mann-Whitney (U) and Kruskal-Wallis $\left(\chi^{2}\right)$ Tests

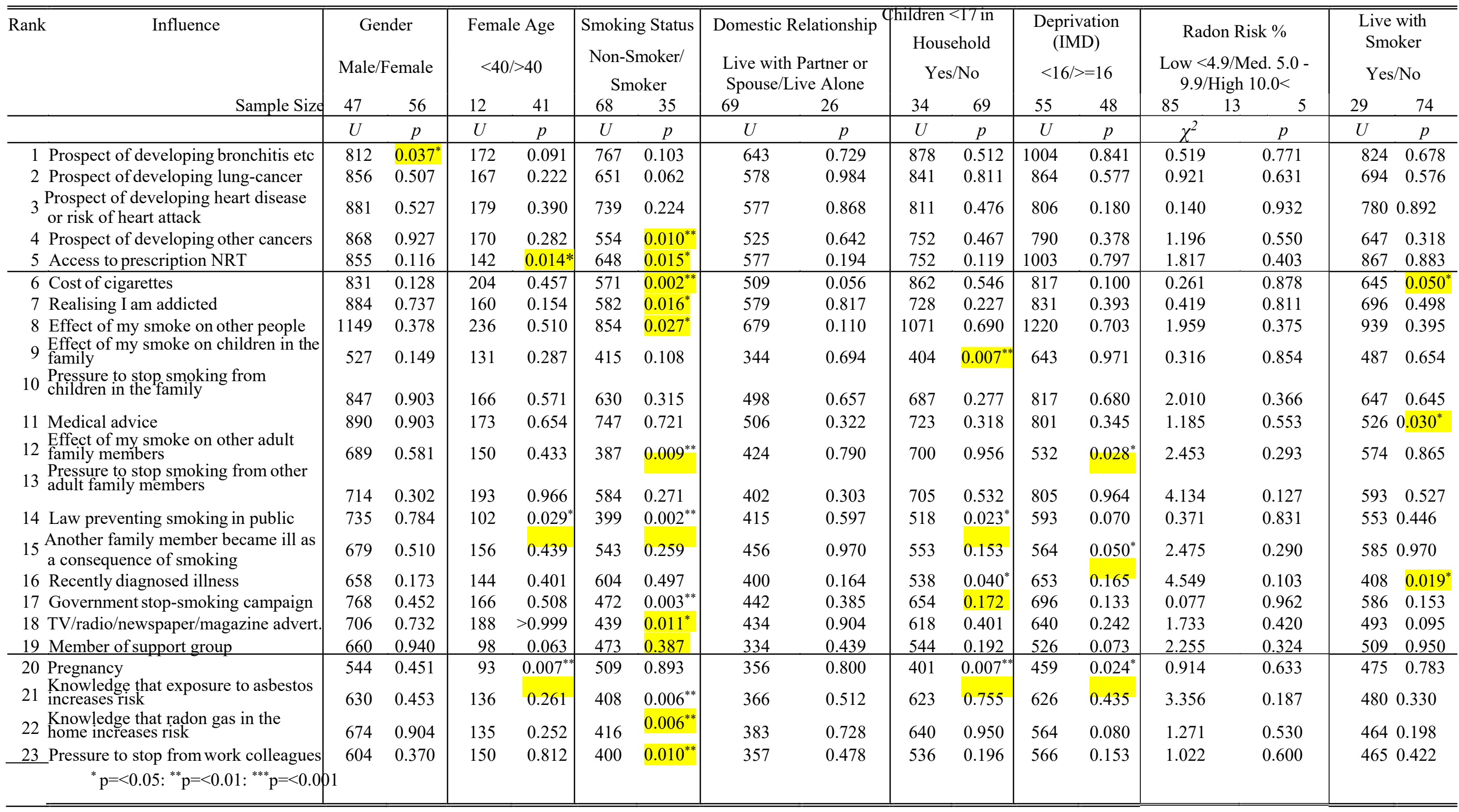

